\title{
Equity versus equality norms of justice and organisational commitment: the moderating role of gender
}

Research Article

Nagarajan Ramamoorthy* and Donna Stringer

School of Business Administration, Department of Management

and Marketing, University of Houston-Victoria, United States of America

Abstract: In the current study, using a sample of 467 employees from Ireland, we examined the effects of distributive justice perceptions, based on equity versus equality principles, on two forms of employee commitment: affective and normative. Furthermore, we also tested whether employees' gender moderated the relationships between these two distributive justice perceptions and the two forms of commitment. Results indicated that equity perceptions positively influenced both forms of commitment and equality perceptions positively influenced only normative commitment. Additionally, results revealed that women reported greater affective and normative commitments than men when equity perceptions were higher than when they were lower. Gender did not moderate the relationship between equality perceptions and normative commitment. Women, however, reported lower affective commitment than men when equality perceptions were lower; there were no differences between men and women on affective commitment when equality perceptions were higher. Implications are discussed.

Keywords: distributive justice; equality norms; equity perceptions, gender; organisational commitment

(C) De Gruyter Open Sp. z 0.0.

\section{INTRODUCTION}

In the organisational behaviour and management literature, the role of organisational commitment in influencing a variety of work-related behaviours (such as job performance and employee turnover) and attitudes (such as job satisfaction) has been a dominant area of research for several decades. Research on organisational commitment has identified three different forms of commitment: affective, normative, and continuance (Allen and Meyer, 1990; Meyer and Allen, 1991; Mowday et al., 1982). While affective commitment refers to the emotional ties one experiences with regard to an organisation, normative commitment reflects a sense of loyalty to the organisation and obligation towards the goals of the organisation. Allen and Meyer (1990) refer to normative commitment as 'internalized normative pressures to act in a way which meets organisational goals and interests'. Finally, continuance commitment refers to an obligation based on costs associated with being a member of the organisation and generally focusses on the switching costs associated with severing ties with the organisation (Meyer and Allen, 1991). However, except in the case of research regarding organisational exit (Cooper-Hakim and Viswesvaran, 2005; Johnson et al., 2009a,b; Payne and Huffman, 2005; Taing et al., 2011), the literature on organisational commitment generally has focussed on affective and normative components (Cropanzano and Folger, 1991). Further, studies on organisational justice have identified distributive justice perception as an important dimension that influences organisational commitment (CohenCharash and Spector, 2001; Colquitt et al., 2001).

The notion of distributive justice focusses on the distribution of outcomes (e.g., rewards and incentives) and the perceived fairness of outcomes. Deutsch (1975) suggested that distribution of outcomes may be based on equity, equality, or need norms. Despite this suggestion, much of the research on distributive justice-commitment relationships have focussed on equity theory (Adams, 1965), with a few cross-cultural studies that have focussed on the equity versus equality norms (e.g., Chen et al., 1998; Kim et al., 1990; Leung and Iwawaki, 1988). Additionally, thus far, studies on organisational justice have examined the influence of justice perceptions from the point of view of equitable distributions and not from the point of view of alternative form of equality-based distribution. Thus, one goal of the 
current study is to examine the influence of justice perceptions based on equity versus equality norms on employee commitment (affective and normative). We chose to focus on these two components of commitment since continuance commitment refers to a 'locked in' relationship and is concerned with the cost of switching organisations and may not have much relevance to justice perceptions.

A second related but important goal of the current study is to examine whether an employee's gender moderates the relationships between equity- versus equality-based justice perceptions on employee commitment. Studies on gender and pay indicate that women tend to be underpaid than men due to both access discrimination and pay discrimination (Milkovich et al., 2014). In the context of pay, despite the European Union's initiative to narrow the wage gap between men and women, Zeigler (2006: 213) points out the wage gap between men and women as 'breadwinner's wage for men and a pin money wage for women working the same jobs' and it is estimated that women earn only about $82 \%$ of men's wages in the European Union. Since then, varied attempts have been made to bring women and men to parity with regard to employment decisions (e.g., pay and promotion opportunities). Recent studies (e.g., Cha and Weeden, 2014; Werner and Ones, 2000) suggest that pay differences based on gender are either nonexistent or have narrowed considerably, suggesting a relatively more level playing field for men and women.

Although pay disparities and justice perceptions are distinctly different, they are in some way related. First, initial wage disparities between men and women might have had to do with historical access discrimination, such as inaccessibility of women to certain higher-paying jobs (Eagly and Karau, 2002), perhaps due to glass ceiling effects that prohibited upward mobility of women in the organisational hierarchy or glass wall effects that prohibited women from horizontal mobility to functional areas that command higher wages. A recent meta-analytic study by Roth et al. (2012) found that women were rated higher on job performance than men but promotability ratings were higher for men than for women, suggesting that access to higher-paying jobs and promotions might be subjective decisions and an obstacle that women have to overcome. A second but related argument has to do with how do firms narrow these wage gaps? Though firms may follow distributive justice norms based on equity versus equality norms to address these disparities, do these norms have a differential effect on the levels of both forms of commitment? Previous studies regarding distributional fairness tend to indicate that women prefer distributions that are either equal (Cook and Hegtvedt, 1983) or consistent with status difference expectations (Wagner, 1995). Jepsen and Rodwell (2009) reported that men and women perceive justice differently, with women being more concerned with relational issues and men more focussed on material issues such as money and reward. Thus, a second goal of the current study is to examine the moderating role of distributive justice perceptions based on equity versus equality norms since one focusses on the material component and the other on the relational component.

Given such differences in the wages between men and women, one should also expect that a higher level of distributive justice perception should have a more profound impact on the commitment of women than men as distributive fairness should enable them to narrow the wage gap. In this context, we believe that equity norms may enable women to narrow the differences in earnings compared to men and perceptions of equity should result in more positive effects on the commitment for women than for men. Though equality-based rewards might not help narrow the wage differentials between men and women, they do serve the purpose of conveying equal treatment in pay distribution and emphasise relational values more than material values, which may be more congruent with women's value systems. Thus, women might view lack of equal rewards negatively and may tend to exhibit lower commitment than men. Thus, there is still much to be learned about how gender changes the relationships between justice and commitment. We seek to test the hypothesis that gender moderates the relationship between the two types of commitment and the two types of justice perceptions.

Thus, our goal is to examine the perceptions of equity versus equality in reward distribution on the two forms of commitment (affective and normative) and whether gender moderates these relationships. We test these research questions using survey data collected from 467 employees in Ireland. In the literature review, we develop the hypotheses based on the literature and then follow up with a section on the methodology used to test these hypotheses. We present the results of our study and conclude with implications of our study for research and managerial practices.

\section{REVIEW OF THE LITERATURE}

\section{The nature of organisational commitment}

Research on organisational commitment has identified affective, normative, and continuance modes as the three components of organisational commitment. Allen and Meyer conceptualised organisational commitment as a non- 
exclusive psychological state (Allen and Meyer, 1990; Meyer and Allen, 1991) and thus extend the work of Mowday et al. (1982), who defined commitment as an affective response. Affective commitment reflects an emotional attachment to the organisation. Normative commitment, on the other hand, is based on an obligation rule and refers to identification with the goals of the organisation. The final component of commitment refers to continuance commitment and involves an evaluation of the cost and benefit of quitting an organisation based on investments an employee has made in the organisation.

Several studies (e.g., Ramamoorthy and Flood, 2004) have shown that both affective and normative commitments, despite being separate components of commitment, are highly correlated with each other. For example, Soumyaja et al. (2011) have found affective and continuance commitment to be clearly separable, with normative commitment being related to both affective and continuance commitment. In a study of organisational attachment, Schusterschitz et al. (2011: 345) indicate that affective commitment is correlated with both continuance and normative commitment; further, the affective-normative commitment relationship was stronger than the relationships with continuance commitment.

Researchers have provided evidence that a number of individual differences would yield different relationships with the various components of commitment. For example, several recent studies have found gender differences for commitment (Gonzalez and DeNisi, 2009; Linz, 2004; Martín, 2008; Messarra and Karkoulian, 2008). In a study of global versus facet measures of intent to quit, Campbell and Campbell (2003) found that men reported lower commitment than women; however, further analysis uncovered a different pattern when individual facets were used to predict intention to quit, resulting in the authors concluding that role socialisation may be a factor in the discrepancy between global and facet relationships. Linz (2004) found that women were less likely to change organisations for pay increases than were men and attributed this to the traditional role of women being caregivers than primary income earners. In a sample drawn from organisations in Spain, Martín (2008) noted that gender, among other variables, served to moderate the relationship between antecedents and dimensions of organisational commitment. Several meta-analytic studies (e.g., Cohen-Charash and Spector, 2001; Colquitt et al., 2001; Li and Cropanzano, 2009) have demonstrated that organisational justice perceptions are important antecedents of both affective and normative commitment.

\section{Distributive justice norms}

Organisational justice refers to fairness in the workplace in terms of workplace practices. Prior research (e.g., Cohen-Charash and Spector, 2001; Colquitt et al., 2001) shows that organisational justice is a multi-dimensional construct involving distributive, procedural, and interactional components. While distributive justice refers to an individual's evaluation of the fairness of the outcome (e.g., distribution of rewards), procedural justice refers to the fairness of the processes used in the allocation of rewards and is grounded in the dispute resolution theory (Thibaut and Walker, 1975). Finally, interactional justice, introduced to the literature by Bies and Moag (1986), has a focus on the quality of interpersonal relationships in the workplace (Ramamoorthy and Flood, 2004).

Though all three dimensions of organisational justice perceptions are related to commitment, in the current study, we focus specifically on distributive justice and its decision rules. While the original conceptualisation of distributive justice norm referred to equity theory (Adams, 1965), subsequent formulations of distributive justice norms include equality and needs as well (Deutsch, 1975; Leventhal, 1976). The equity rule is based on the premise that rewards should be consistent with the inputs and contributions of the individual to the organisation. The norms of equity suggest that each individual must be rewarded in proportion to his or her contribution. In the organisational justice literature, researchers often use the term equity or pay for performance interchangeably to reflect equity norms in reward allocation. While critics (e.g., Cox, 1993; Pfeffer, 2007) argue that distributive justice norms based on the principle of equity promote competition among employees, its motivational effect on employees has been well documented as several studies show that equity norms or pay for performance principles result in greater commitment, lower employee turnover, and superior performance (e.g., Cropanzano et al., 2007; Haar and Spell 2009; Harris et al., 2007; Li and Cropanzano, 2009; Lowe and Vodanovich, 1995). In a more recent meta-analysis, $\mathrm{Li}$ and Cropanzano (2009) report correlations of 0.31 and 0.42 between distributive justice and organisational commitment, depending on whether the sample is East Asian or North American, respectively. When individuals perceive that the organisation recognises and rewards their effort and contribution, employees may engage less in shirking and social loafing behaviours but may be motivated to do a better quality work. Equity theory, with its focus on the fairness of the exchange relationships, would suggest that employees feel obliged to reciprocate when they perceive that they have been treated fairly. Further, a system that focusses on equity norms and rewards individuals for good performance and fails to reward poor performance may also signal to the employees that the organisation 
values good performance regardless of other characteristics of the individuals, such as an employee's gender. Therefore, perceptions of equity in the workplace should result in a liking for the organisation and greater alignment with the norms and goals of the organisation.

Considering these arguments, we propose the following:

H1: Perceptions of equity in reward allocation should be positively related to affective commitment and normative commitment.

Unlike equity norms that reward individuals in proportion to their contribution, the equality norm states that individuals may be rewarded equally in order to promote cooperation as opposed to competition. Although there are studies with up to eight different distribution rules (cf., Conlon et al., 2004), equity and equality are the two most popular rules studied in the field of organisational justice. While equality norm has been suggested to encourage cooperation and teamwork (Cox, 1993), it may also have the unintended consequence of encouraging social loafing and shirking by some employees.

Economic theories of incentives (Baron and Kreps, 1999; Jensen and Meckling, 1976) suggest that in expending effort for the organisation, employees bear the cost of such effort with uncertain outcome in the form of rewards. Some studies (Greenberg et al., 1971) suggest that employees compare the costs versus benefits in evaluating the fairness of the outcome. While organisational practices of reward allocations based on equity provide employees with certain assurances that individuals investing greater effort will receive greater reward, adherence to equality norms may actually signal to employees that employees bear the full cost of their effort but the outcomes are shared equally. This could be potentially problematic in integrative tasks in which employees are expected to cooperate with others on task accomplishment. In such cases, an individual employee's effort is under his or her control but other members may act in an opportunistic and self-interest-seeking manner by not sharing his or her part of the workload. Thus, employees investing greater effort in the expectation that other members of the organisation would reciprocate may actually be taking greater risks in that others may not reciprocate, thus leading to the vulnerability of the cooperating employee. Since individuals are risk averse (Jensen and Meckling, 1976), employees may engage in social loafing and shirking behaviours, particularly when they realise that they would share the outcomes equally regardless of their level of effort. Hence, under equality-based reward systems, employees may exhibit lesser identification with the organisation and its goals, in addition to probably exhibiting lesser attachment to the organisation. Therefore, we propose the following:

H2: Perception of equality in rewards should be negatively related to affective commitment and normative commitment.

\section{Gender and justice norms}

How do men and women perceive different justice norms and modify their attitudes towards the organisation considering the predominant evidence of gender-based disparities in wages? Cha and Weeden (2014) reported that between 1979 and 2009, wage differences between men and women narrowed considerably due to wage equalising trends such as educational attainment of women and labour force experiences such as anti-discriminatory legislations. Further, these authors pointed out that about $10 \%$ of the wage differentials between men and women occur due to overwork of men such as longer work hours. Werner and Ones (2000) also did not find any pay inequities based on gender. Suffice it to say that the true wage differentials based on gender may have narrowed considerably, yet it still exists. Such a reduction in wage differential may also have created a level playing field in the workforce. Yet, perceptions of distributive fairness may still play a role in influencing the attitudes of men and women as opposed to objective distributional rules.

There is some literature to support the moderating effect of gender on the relationships between justice perception and a variety of outcome variables (e.g., Choi, 2011; Foley et al., 2005; Jepsen and Rodwell, 2009; Johnson et al., 2009a,b); yet, other studies show no effect of gender (cf., Liao-Troth, 2001; Peng et al., 2009; Simpson and Kaminski, 2007). Choi (2011) found that both men and women showed high levels of trust, but men did so when they perceived distributive and interpersonal justice, whereas women showed greater trust with the perception of procedural justice. Johnson et al. (2009a,b) report that women perceived higher weights for citizenship behaviours to be fairer than did men. Because of the growing evidence suggesting that there are indeed gender differences for organisational justice when each component is considered separately (Foley et al., 2005; Jepsen and Rodwell, 
2009), it would be prudent to test for an effect of gender in examining relationships with attitudinal variables such as organisational commitment.

In the context of distributive justice perceptions, how do women who are relatively underpaid compared to men, react towards the organisation? Equity theory (Adams, 1965) suggests that individuals may resort to a variety of responses ranging from affective responses, such as lower organisational commitment or lack of internalisation of organisation's goals, to behavioural responses, such as lowering one's own job performance or even quitting the organisation. On the other hand, when individuals perceive distributive fairness in the workplace, they may work in the interest of the organisation. Given that women's earnings are less than men's earnings, equitable rewards in the workplace might be of greater importance to women than to men who have traditionally enjoyed better opportunities than women. In support of this line of reasoning is the concept of self-interest (Sears and Funk, 1991). If the psychological variable of self-interest is highly salient in those who are in a disadvantaged position (Kravitz and Platania, 1993), such as those receiving lower earnings, and pay plays a dominant role in the perceptions of fairness in organisational settings (Anderson and Shinew, 2003), then we could expect females to prefer the mechanism that would offer the greatest opportunity for material well-being. Additionally, perceptions of higher equity in the organisation would also signal to women that the organisation values pay for performance and women, if they perform well, have the opportunity to advance their own earning potentials and career, which may result in higher levels of commitment towards the organisation. Ramamoorthy and Flood (2004) report that women in general reported higher affective commitment than men and the difference between men and women on affective commitment was even more pronounced when distributive justice perceptions were higher. That is, under conditions of higher equity perceptions, women reported much higher level of affective commitment than men rather than when equity perceptions were lower. Considering this line of argument, we propose the following:

H3: Female employees should exhibit greater affective and normative commitment than men when equity perceptions are higher than when they are lower.

With respect to equality-based distributive justice perceptions, the cross-cultural literature (e.g., Kim et al., 1990; Leung and Iwawaki, 1988) has treated equality norms as the opposite of equity norms. At least one study (Ramamoorthy and Carroll, 1998) that measured equity and equality norms directly reported a positive correlation between the two, suggesting that equity- and equality-based norms may exist as independent dimensions of distributive justice norms.

Performance-based reward systems based on equity norms may promote competitiveness and an emphasis on materialistic achievements in the form of higher pay. On the contrary, adherence to equality-based norms in organisations may disregard individual performance differences, encourage cooperation, and focus on organisational or group performance. At the same time, equality-based rewards may encourage shirking and social loafing behaviours when some members of the organisation do not put forth the required effort in the achievement of organisational goals (Baron and Kreps, 1999). Further, studies have shown that women tend to engage in more cooperative behaviours than men and are more oriented towards relationships than success (e.g., Eagly, 1987; Gilligan, 1982). As discussed earlier, perhaps due to their cooperative nature, women might consider the inclusion of citizenship behaviours in performance evaluations to be fairer than men as citizenship behaviours emphasise relational component outcomes more than performance outcomes alone (Johnson et al., 2009a,b). Thus, it is possible that women may perceive that they are engaging in more cooperative behaviours than men and may prefer rewards that are equally shared among all the organisational members though equality-based systems may tend to perpetuate initial pay differences that existed between men and women. However, based on the study of Cha and Weeden (2014), society seems to have narrowed this pay differential, thus creating a level field for men and women. As indicated by the study of Ramamoorthy and Carroll (1998), both equality- and equity-based systems conform to distributive justice norms and are positively related, except that one focusses on individual performance (equitybased systems) and the other focusses less on individual performance (equality-based system). Thus, women may not perceive equality-based systems as unfair or perpetuating the initial pay differences but may find the system to be more congruent with their value system emphasising the relational aspect of work.

Considering this aspect, we propose the following:

H4: Women should exhibit lower affective commitment and normative commitment than men when perceptions of equality-based rewards are lower. 
To summarise, we are proposing that equity-based rewards should positively and equality-based rewards should negatively influence affective and normative commitment. Additionally, we are also proposing that women would report greater commitment under conditions of higher levels of perceived equity-based and lower commitment under conditions of lower perceived equality than men. In the 'Method' section, we discuss the methodology used to test these hypotheses.

\section{METHOD}

\section{Sample}

Four hundred and sixty-seven employees from 13 companies in the Shannon region of Ireland participated in the study. These companies were in different sectors such as insurance, financial services, manufacturing, travel services, pharmaceutical, retail supermarkets, and electronics and thus represented a broad spectrum of industries. As many of the companies were in the service sector, there were more women than men in the sample. The sample consisted of 162 male employees $(34.7 \%)$ and $303(64.9 \%)$ female employees, with data missing for two employees. One hundred and seventeen employees $(25.1 \%)$ were in the age group of $18-$ 25 years, 218 employees (46.7\%) were in the age group of $26-35$ years, 107 employees $(22.9 \%)$ were in the age group of 36-45 years, 21 employees (4.5\%) were in the age group of $46-55$ years, and two $(0.006 \%)$ employees identified themselves as being older than 55 years of age. These employees had on an average worked for 2.31 companies, with a standard deviation of 1.57 employers. The employees reported an average work experience of 9.89 years with the company, with a standard deviation of 4.37 years. We collected data from the employees using a survey. Since the companies permitted us to administer the survey during the work hours, the response rate was $>95 \%$, barring that of a few absentees. These surveys were administered by one of the authors with an assurance of confidentiality to the respondents and anonymously in the absence of the supervisors.

\section{Measures}

We used established measures whenever possible. However, for equality norms, we developed a measure specifically for this study. Due to the time allotted to the researchers by the company for data collection, we had to shorten some of the scales in the survey.

Affective commitment. We measured affective commitment using the Organizational Commitment Questionnaire of Mowday et al. (1979). This scale consisted of the following items: (1) I am willing to put in a great deal of effort beyond that normally expected in order to make my company be successful. (2) I recommend this company to my friends as a great place to work. (3) I am proud to tell others I am part of my company. (4) I am extremely glad that I chose my company to work for over others, and (5) I really care about the fate of my company. Participants' responses were collected using a five-point Likert-type scale with ' 1 = strongly disagree' and ' $5=$ strongly agree' as anchors. This scale exhibited a Cronbach's alpha of 0.85 . Data coding was done in such a way that a higher score indicated a higher level of affective commitment.

Normative commitment. We assessed normative commitment using four items from Allen and Meyer's (1990) scale. The short form of normative commitment has been used and validated in a prior study (Ramamoorthy and Flood, 2004). These four items were the following: (1) It is not right for me to leave the company even if it were to my advantage; (2) I feel guilty if I left the company now; (3) The company deserves my loyalty; and (4) I owe a great deal to the company, with ' $1=$ strongly disagree' and ' $5=$ strongly agree' as anchors. The Cronbach's alpha of this scale was 0.79 . Data coding was done in such a way that a higher score indicated a higher level of commitment.

Distributive justice perceptions. We measured equality perceptions in reward distributions using the two items from Cloninger et al. (2011) as the literature search did not reveal any other measure for equality perceptions: 'In our company, monetary rewards are distributed more equally among employees', and 'In allocating monetary rewards, our company follows equality norm most often', with ' 1 = strongly disagree' and ' $5=$ strongly agree' as anchors. We measured equity perceptions in reward distributions using the following two items from Flood et al. (2001): 'I am fairly rewarded for the amount of effort I put in' and 'I am fairly rewarded for the responsibilities I take on', with ' $1=$ strongly disagree' and ' $5=$ strongly agree' as anchors.

We subjected these four items to factor analysis using principal component analysis with varimax rotation. Results of this analysis confirmed the a priori existence of two factors with two equity items measuring equity 
and two equality items measuring equality norms of distributive justice perceptions. The two equity items loaded on the first factor with a factor loading of 0.92 , accounting for $43.28 \%$ of the variance. The two equality items loaded on the second factor with a factor loading of 0.88 and accounted for $39.62 \%$ of the variance. The two-item scale for equity perceptions yielded a coefficient alpha of 0.85 , and the two-item scale for measuring equality perceptions yielded a coefficient alpha of 0.73 . We coded the data such that a higher score indicated a higher level of equality and equity perceptions.

Gender. We coded male as 0 and female as 1.

Importance of salary. Individuals differ in terms of their level of sensitivity to reward equity or inequity, which may be affected by the importance they attach to material issues such as salary (Jepsen and Rodwell, 2009), with men more focussed on materialism and women on relational issues. Hence, we asked the respondents to indicate how important salary was to them using a three-point scale, with $1=$ most important and $3=$ least important. We used importance of salary as a surrogate for equity sensitivity and controlled for it in testing our hypotheses.

\section{Data analysis strategy}

Hypotheses 1 and 2 suggest main effects of equity perceptions and equality perceptions on affective and normative commitments. Hypotheses 3 and 4 suggest that gender moderates the relationships between equity versus equality perceptions and the two commitment variables - affective and normative. In order to test hypotheses 1 and 2 (main effects), we used hierarchical regression analyses. In order to test hypotheses 3 and 4 , we used moderated regression analyses as suggested by Pedhazur (1982). In order to test the moderation effects, we created two interaction terms (gender $\times$ equity perceptions and gender $\times$ equality perceptions). In the first step, we entered the two control variables, gender and salary (model 1 in Tables 2 and 3). In the second step, we entered the main effects, equity or equality perceptions (model 2 in Tables 2 and 3); and finally, in the third step, we entered the interaction term (equity $\times$ gender or equality $\times$ gender (model 3 in Tables 2 and 3 ). We used the incremental $F$-ratio test to examine the statistical significance of the model and one-tailed $t$-tests for betas to assess the statistical significance of the predictor variables. The hypothesised moderation effects would be supported if the interaction terms are statistically significant. Whenever the interaction terms were significant, we used the -1 and +1 standard deviations to decompose the interaction terms.

\section{RESULTS}

Table 1 presents the mean values, standard deviations, and correlations among the variables used in the study. Table 2 presents the results of the hierarchical and moderated regression analyses examining the effect of equity perceptions on the two commitment variables. Table 3 presents the results of the hierarchical and moderated regression analyses examining the effect of equality perceptions on the two commitment variables.

Table 1. Descriptive statistics and correlations among variables used in the study

\begin{tabular}{|c|c|c|c|c|c|c|c|}
\hline Variables & Mean & $\mathbf{s}$ & Gender & Salary & $\begin{array}{c}\text { Equity } \\
\text { Perception } \\
\end{array}$ & $\begin{array}{c}\text { Equality } \\
\text { Perception }\end{array}$ & $\begin{array}{c}\text { Affective } \\
\text { Commitment }\end{array}$ \\
\hline Gender & 0.66 & 0.48 & & & & & \\
\hline Salary importance & 1.61 & 0.65 & $0.15^{\star \star \star *}$ & & & & \\
\hline Equity perceptions & 3.03 & 1.05 & $-0.09^{*}$ & $0.11^{*}$ & & & \\
\hline Equality perceptions & 2.82 & 0.87 & -0.02 & -0.01 & $0.19^{\star \star \star}$ & & \\
\hline Affective commitment & 3.54 & 0.88 & -0.04 & $0.18^{\star * *}$ & $0.41^{* * *}$ & 0.05 & \\
\hline Normative commitment & 2.65 & 0.91 & -0.04 & $0.10^{*}$ & $0.36^{\star * *}$ & $0.14^{\star \star *}$ & $0.56^{\star \star \star}$ \\
\hline
\end{tabular}


Table 2. Results of the moderated regression analysis on affective commitment and normative commitment: effect of equity norms

\begin{tabular}{|c|c|c|c|c|c|c|c|c|c|c|c|c|}
\hline \multirow{3}{*}{ Variables } & \multicolumn{6}{|c|}{ Affective Commitment } & \multicolumn{6}{|c|}{ Normative Commitment } \\
\hline & \multicolumn{2}{|c|}{ Model 1} & \multicolumn{2}{|c|}{ Model 2} & \multicolumn{2}{|c|}{ Model 3} & \multicolumn{2}{|c|}{ Model 1} & \multicolumn{2}{|c|}{ Model 2} & \multicolumn{2}{|c|}{ Model 3} \\
\hline & $\mathbf{b}$ & $\mathbf{t}$ & $\mathbf{b}$ & $\mathbf{T}$ & $\mathbf{b}$ & $\mathbf{t}$ & b & $\mathbf{t}$ & $\mathbf{b}$ & $\mathbf{t}$ & $\mathbf{b}$ & $\mathbf{t}$ \\
\hline Salary & 0.19 & $4.14^{\star \star *}$ & 0.14 & $3.36^{* \star *}$ & 0.15 & $3.48^{\star * \star}$ & 0.11 & $2.33^{* *}$ & 0.07 & 1.52 & 0.07 & 1.61 \\
\hline $\begin{array}{l}\text { Gender } \\
(\text { male }=0 ; \text { female }=1)\end{array}$ & -0.07 & 1.42 & -0.02 & 0.54 & -0.42 & $3.36^{\star * *}$ & -0.06 & 1.21 & -0.02 & 0.44 & -0.42 & $3.23^{\star \star \star}$ \\
\hline Equity & & & 0.40 & $9.40^{* \star *}$ & -0.04 & 0.29 & & & 0.35 & $7.89^{\star \star \star}$ & -0.09 & 0.67 \\
\hline Gender $\times$ equity & & & & & 0.58 & $3.37^{\star * \star}$ & & & & & 0.59 & $3.26^{\star \star \star}$ \\
\hline $\mathrm{D} R^{2}$ & 0.04 & & 0.15 & & 0.02 & & 0.01 & & 0.12 & & 0.02 & \\
\hline F & $8.90^{\star \star \star}$ & & $88.36^{\star * *}$ & & $11.33^{\star \star \star}$ & & $3.09^{*}$ & & $62.23^{* * *}$ & & $10.65^{\star \star \star}$ & \\
\hline
\end{tabular}

Table 3. Results of the moderated regression analysis on affective commitment and normative commitment: effect of equality norms

\begin{tabular}{|c|c|c|c|c|c|c|c|c|c|c|c|c|}
\hline \multirow{3}{*}{ Variables } & \multicolumn{6}{|c|}{ Affective Commitment } & \multicolumn{6}{|c|}{ Normative Commitment } \\
\hline & \multicolumn{2}{|c|}{ Model 1} & \multicolumn{2}{|c|}{ Model 2} & \multicolumn{2}{|c|}{ Model 3} & \multicolumn{2}{|c|}{ Model 1} & \multicolumn{2}{|c|}{ Model 2} & \multicolumn{2}{|c|}{ Model 3} \\
\hline & $\mathbf{b}$ & $\mathbf{t}$ & b & $\mathbf{t}$ & $\mathbf{b}$ & $\mathbf{t}$ & $\mathbf{b}$ & $\mathbf{t}$ & b & $\mathbf{t}$ & b & $\mathbf{t}$ \\
\hline Salary & 0.20 & $4.25^{\star * *}$ & 0.20 & $4.25^{\star * *}$ & 0.21 & $4.47^{* \star \star}$ & 0.11 & $2.25^{*}$ & 0.11 & $2.28^{*}$ & 0.11 & $2.32^{*}$ \\
\hline $\begin{array}{l}\text { Gender } \\
(\text { male }=0 ; \text { female }=1)\end{array}$ & -0.06 & 1.39 & -0.06 & 1.37 & -0.46 & $3.02^{\star \star}$ & -0.06 & 1.29 & -0.06 & 1.23 & -0.15 & 0.99 \\
\hline Equality & & & 0.05 & 1.03 & -0.35 & $2.29^{\star \star}$ & & & 0.14 & $2.99 * *$ & 0.04 & 0.29 \\
\hline Gender $\times$ equality & & & & & 0.56 & $2.73^{\star \star}$ & & & & & 0.13 & 0.64 \\
\hline $\mathrm{D} R^{2}$ & 0.04 & & 0.00 & & 0.02 & & 0.01 & & 0.02 & & 0.00 & \\
\hline$F$ & $9.30^{\star \star \star}$ & & 1.06 & & $7.47^{\star \star *}$ & & $3.00^{*}$ & & $8.91^{* *}$ & & 0.41 & \\
\hline
\end{tabular}

Note: ${ }^{*} p<0.05 ;{ }^{* *} p<0.01 ;{ }^{* \star \star} p<0.001$.

Hypothesis 1 suggested that equity perceptions should be positively related to affective and normative commitments. The results of hierarchical regression with equity perceptions as the predictor variable (models 2 in Table 2) provided support for our hypotheses. Equity perception explained an additional $15 \%$ of the variance in predicting affective commitment $\left(F_{3,463}=88.36, p<0.001\right)$ and an additional $12 \%$ of the variance in predicting normative commitment $\left(F_{3,463}=62.23, p<0.001\right)$. Further, the betas for equity perceptions in predicting affective commitment $(\mathrm{b}=0.40, t=$ $9.40, p<0.001)$ and normative commitment $(b=0.35, t=7.89, p<0.001)$ were both positive and significant.

Hypothesis 2 predicted that equality perceptions should be negatively related to affective and normative commitments. The results of hierarchical regression with equality perceptions as the predictor variable (models 2 in Table 3) failed to provide support for our hypotheses. Equality perception did not explain any additional variance in predicting affective commitment $\left(F_{3,463}=1.06, p<0.001\right)$. Although equality perception explained an additional $2 \%$ of the variance in predicting normative commitment $\left(F_{3,463}=8.91, p<0.01\right)$, the beta for equality perception in predicting normative commitment $(b=0.14, t=2.99, p<0.05)$ was positive and not negative. That is, our results show that perceived equality in rewards positively, rather than negatively, influences normative commitment.

Hypothesis 3 predicted that gender would moderate the relationships between equity perceptions and the two commitment variables - affective and normative - in such a way that women would report greater commitment under conditions of higher perceived equity. The results of moderated regression with equity perceptions as the predictor variable (models 3 in Table 2) provided support for our hypotheses. The interaction term between gender $x$ equity perceptions explained an additional $2 \%$ of the variance in predicting affective commitment $\left(F_{4.462}=11.33, p<\right.$ $0.001)$ and an additional $2 \%$ of the variance in predicting normative commitment $\left(F_{4,462}=10.65, p<0.001\right)$. Further, the betas for the interaction term gender $\times$ equity perceptions in predicting affective commitment $(b=0.58, t=3.37$, $p<0.001)$ and normative commitment $(b=0.59, t=3.26, p<0.001)$ were both positive and significant. Figures 1 and 2 present the moderating effects of gender on the relationships between equity perceptions and the two forms of commitment (affective and normative). 
Figure 1. Moderating effect of gender on the relationship between equity perceptions and affective commitment.

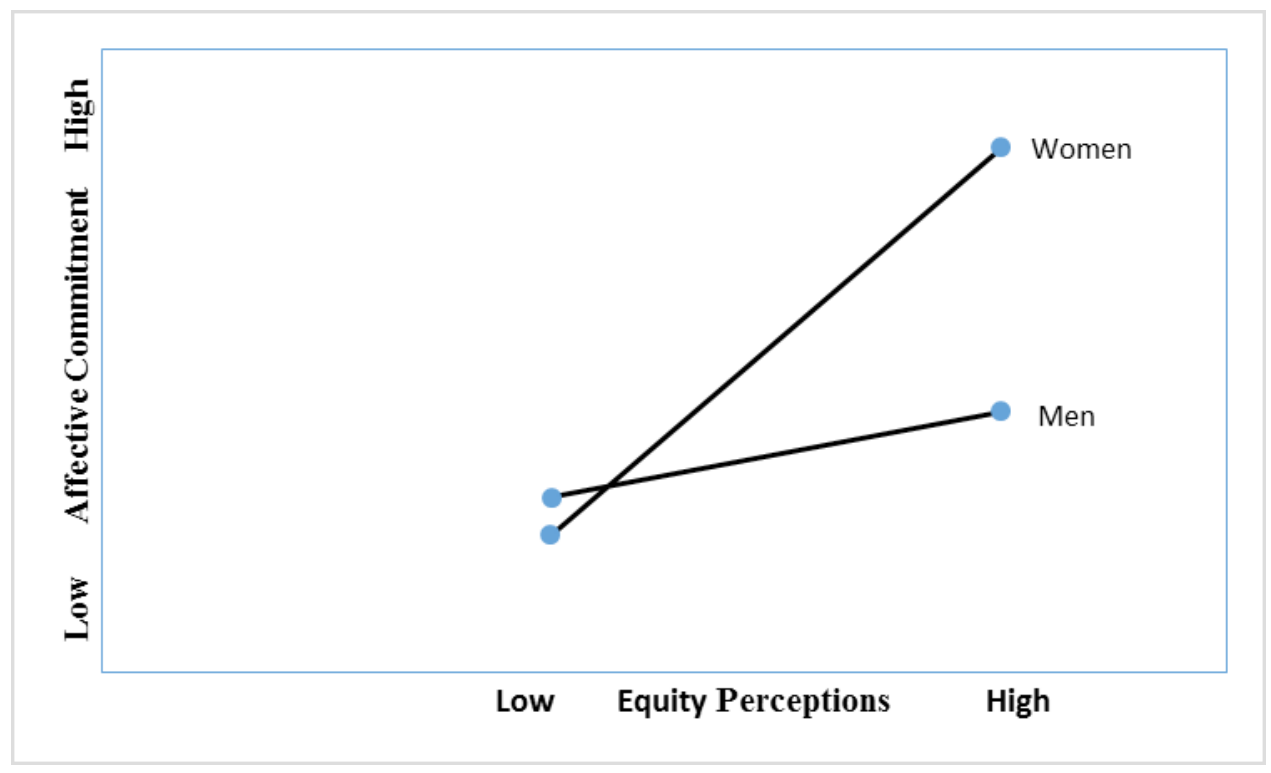

Figure 2. Moderating effect of gender on the relationship between equity perceptions and normative commitment.

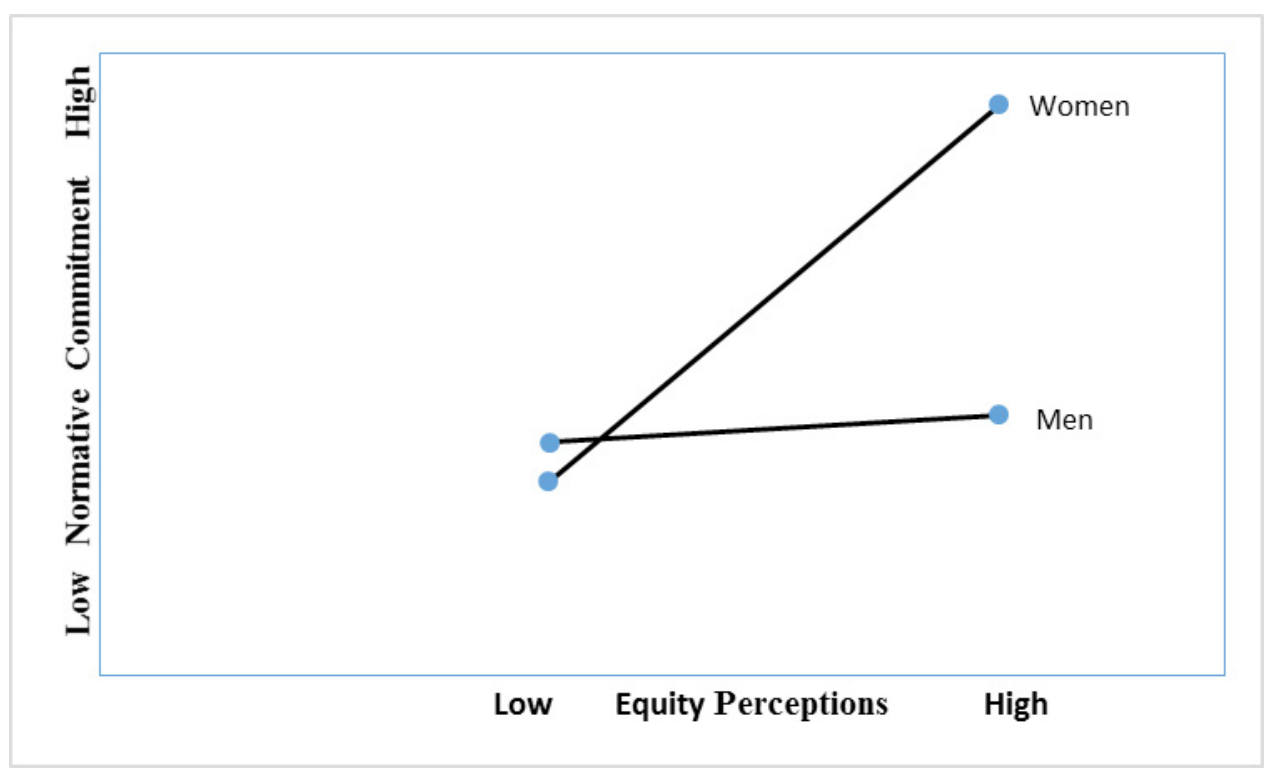

As indicated by Figures 1 and 2, women exhibited greater affective and normative commitment towards the organisation than men when equity perceptions were higher. There were no statistically significant differences between men and women when equity perceptions were lower, indicating that regardless of gender, lower equity perceptions result in lower affective and normative commitment, which is consistent with past results (Ramamoorthy \& Flood, 2004)..

Hypothesis 4 predicted that gender would moderate the relationships between equality perceptions and the two commitment variables - affective and normative - in such a way that women would report lower commitment under conditions of lower perceived equality. The results of moderated regression with equality perception as the predictor variable (models 3 in Table 3) provided partial support for our hypotheses. The interaction term between gender $\times$ 
equality perceptions explained an additional $2 \%$ of the variance in predicting affective commitment $\left(F_{4,462}=7.47, p<\right.$ $0.001)$. However, the interaction term between gender $\times$ equality perceptions did not explain any additional variance in predicting normative commitment $\left(F_{4,462}=0.41, p>0.05\right)$. Further, the beta for the interaction term gender $\times$ equality perception in predicting affective commitment $(b=0.56, t=2.73, p<0.01)$ was positive and significant. Figure 3 presents the moderating effect of gender on the relationships between equality perception and affective commitment.

Figure 3. Moderating effects of gender on the relationship between equality perceptions and affective commitment.

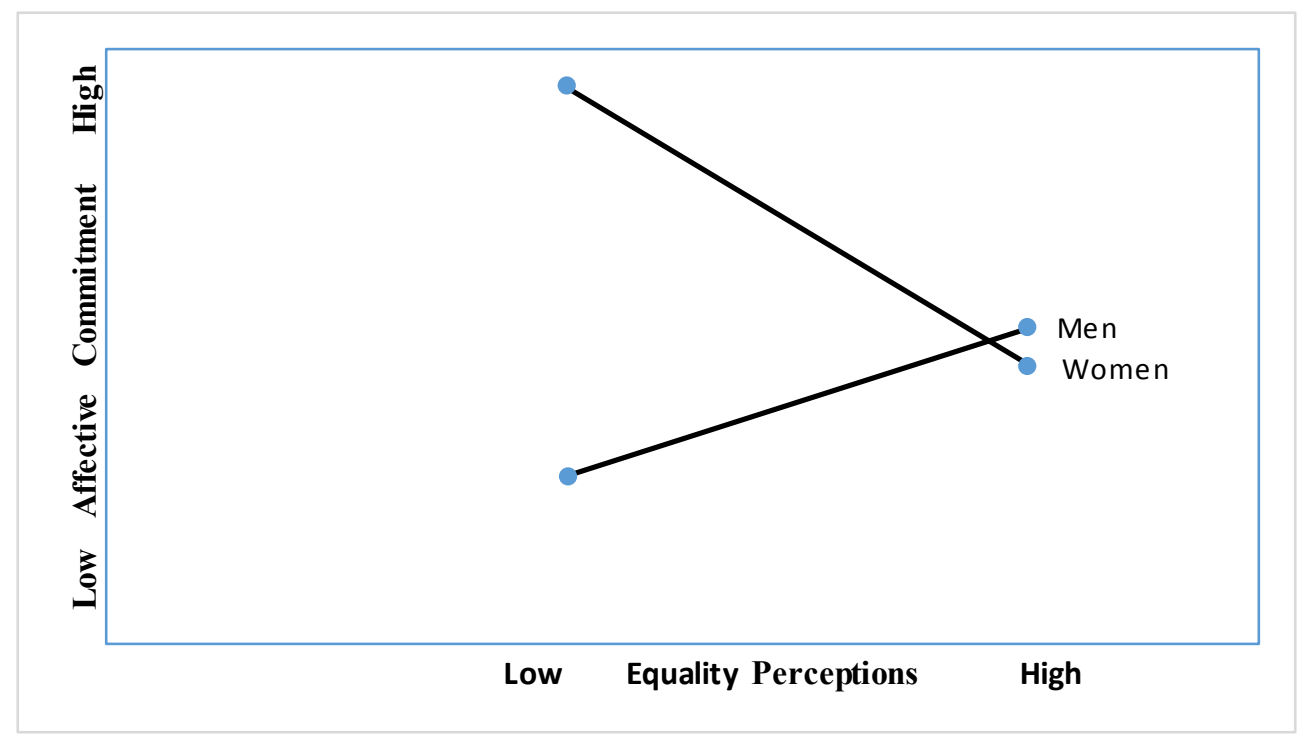

As indicated by Figure 3, when equality perceptions were higher, both men and women did not significantly differ in their affective commitment to the organisation; however, women reported lower affective commitment to the organisation than men when they reported lower equality perceptions. That is, it appears that when women perceive that rewards were not distributed equally, they tend to show lower affective commitment towards the firm. Thus, hypothesis 4 was supported only with respect to affective commitment and not normative commitment.

\section{DISCUSSION}

The current study had two goals in mind. First, we wanted to examine whether perceptions of alternative reward systems based on two distinct distributive justice norms - equity versus equality - influenced affective and normative commitments differently. Second, given the pay inequities that exist in organisations between men and women, we were also interested in examining whether the relationships between perceptions of these two distributive justice norms and the two forms of commitments were moderated by an employee's gender. Several conclusions can be drawn from the findings of our study.

Consistent with prior studies (Cohen-Charash and Spector, 2001; Colquitt et al., 2001), equity perceptions positively influenced affective and normative commitments in the current study. Additionally, we found that there was a clear moderating role of gender on commitment (both affective and normative). For women (but not for men), greater perceptions of equity were associated with greater affective commitment and normative commitment. The results of the current study seem to be somewhat contradictory to the results reported by Ramamoorthy and Flood (2004). Similar to their findings, we also found that under conditions of greater equity perceptions, women reported greater affective and normative commitment than men. However, unlike Ramamoorthy and Flood (2004), in our study, when equity perceptions were lower, there were no significant differences between men and women in the two forms of commitment. The current study also seems to open up an interesting arena of research for 
the future. The two constructs, materialistic values and perceptions of equity, may be distinct. Since we controlled for importance of value attached to pay in our study and yet women tended to report greater commitment under conditions of higher equity perceptions, the results seem to suggest that holding the materialistic values constant, women may still prefer equity in the workplace and organisations that provide an equitable work environment may well reap the benefits in the form of higher levels of commitment from women.

From a woman's perspective, this finding represents an opportunity. For instance, if they perform well, they could expect to be rewarded accordingly and have an opportunity to narrow the inequities in pay. Such an opportunity to narrow wage differentials may also translate into greater emotional ties to the organisation. It could well be that women were sensing a stronger bond to the organisation through the norm of reciprocity. For men, there was no change in commitment (either affective or normative) as a result of increased sense of equity. In the context of this study, pay was the focal outcome. It could be that women are more sensitive to changes in perceived fairness with regard to an outcome that has historically been and continues to be just out of reach of parity with men. Roth et al. (2012) studied performance appraisal ratings and promotability ratings between men and women and found no differences between men and women in performance ratings, but women were rated lower on promotability ratings. To the extent that such differential ratings influence career progression, women may perceive injustice in the workplace. Thus, future studies should also examine other forms of inequities that may exist between men and women (e.g., career opportunities in terms of upward and horizontal mobility, networking to enhance one's own career).

With respect to perceptions of equality norms, clearly a higher emphasis on equality norms tended to result in more positive outcome in the form of increased normative commitment but not affective commitment. Since normative commitment relates to an individuals' tendency to internalise the organisation's goals, equality-based reward systems seem to facilitate this process through its emphasis on cooperation among organisational members regardless of their gender. That is, gender did not moderate the relationships between equality perceptions and normative commitment. However, gender seemed to play a role in the relationship between perceptions of equality in reward systems and affective commitment. While both men and women did not differ in terms of their affective commitment when equality perceptions were higher, there were significant differences between them when equality perceptions were lower. That is, women tended to report lower affective commitment than men when equality perceptions were lower. As prior studies (e.g., Cook and Hegtvedt, 1983; Jepsen and Rodwell, 2009) showed that women tend to be more sensitive to relational issues than men, unequal distribution of rewards in the organisation may send a signal to women in particular that relational and citizenship aspects of work are not valued much in the firm and hence, women may find an incongruence between their values and the organisational reward systems. We should also note that our measure of equity perceptions clearly referenced monetary rewards but the measure of equality perceptions did not. Future studies should focus on developing a reliable and valid instrument to measure the three different forms of distribution rules: equity, equality, and need.

From a practical point of view, organisations grapple with the dilemma of designing reward systems that would motivate employees to perform maximally and elicit positive attitudes. In general, both forms of reward systems tend to promote positive attitudes in the form of normative commitment though equity norms influenced affective commitment only. From the perspective of gender diversity in organisations, lack of pay for performance systems based on equity norms seems to be disliked by both men and women, resulting in lower levels of attitudinal commitment to the organisation, as evidenced in the current study. Equity-based reward systems may have the unintended negative consequences of promoting competitiveness compared to equality-based systems, yet they may be favoured by women more than men. Similarly, equality-based reward systems also appear to be acceptable to both men and women. While managers may be tempted to adhere to equality-based norms to promote cooperation, they must also be aware of the more negative attitude women may exhibit towards such a system, particularly when they perceive lower equality in the workplace. We are not suggesting that organisations must eliminate equality-based reward systems but must be cognisant of the negative consequences it may have on female employees. Given a diverse workforce facing organisations and increased participation of women in the workplace, organisations should also understand that equality-based norms may not be viewed very positively by women when they perceive the organisation to be violating equality norms (lower perceptions of equality).

Further, research in the area of distributive justice should not construe deviations from equity norms as the equivalent of equality or need norms. While individual pay for performance systems tends to measure individual performance and reward individuals according to their relative contributions, there could be situations (e.g., group work on integrated tasks) where measuring and rewarding individual performance might be difficult. In such cases, 
organisations may reward everyone in the group equally through a bonus or incentive payment for successful task accomplishment. Thus, practical difficulties in measurement of individual performance may result in departures from equity norms and such departures from equity norms may not indicate adherence to equality norms. Therefore, future studies should attempt to systematically measure these perceptions directly in order to reach meaningful conclusions.

\section{LIMITATIONS AND DIRECTIONS FOR FUTURE RESEARCH}

We would also like to address some of the limitations of the current study. The study was cross-sectional in nature. As such, causality cannot be inferred. However, as Spector (2006) points out, in organisational research, cross-sectional studies would be a useful starting point. That is, particularly in organisational settings where experimental designs are more difficult to design and implement, cross-sectional studies are quite useful in understanding the relationships between critical variables. In order to address causality, researchers should use controlled experimental designs that vary in terms of equity versus equality norms in distribution of outcomes and examine the impact of such norms on employee attitudes. Alternatively, longitudinal studies may also be a viable option to address the issue of changes in attitudes as a result of changing distributive justice norms based on equity versus equality.

In the current study, we used self-report attitudinal survey to gather data. One of the potential dangers of selfreport is that of common method bias. Common method bias can occur when multiple measures are collected by the same method, particularly at the same time. Future studies can be conducted in such a manner as to minimise common method bias using the survey method or obtain independent data from organisations on such measures as performance or reward information.

In some instances, the items used to assess the variables were modified from existing scales. Moreover, some of the variables were measured with as few as two items. Previous studies from which we measured equity and equality norms have demonstrated good reliability. While the use of a small number of items is not really problematic, future studies may also consider developing scales to measure equality norms with a larger number of items and examine whether reliability can be increased further.

The data were collected during working hours at the participating organisations. As such, there could be potential issues with response bias. The researcher administered the surveys in the absence of supervisors or other company executives ensuring anonymity. Therefore, we do not have any reason to believe that the responses were biased. However, we cannot completely rule out response bias, which tends to be quite common in field studies. Future research must also employ a more rigorous design to rule out possible response biases. Until then, we suggest interpreting our results with caution.

The study was carried out in Ireland, a Western, developed nation. Prior studies also tend to report Ireland to be an individualistic culture endorsing equity norms. Therefore, the generalisability of the results may be limited to similar cultures. Additionally, Ireland also has more stringent equal employment opportunity legislations than some of the other countries in Asia or Africa. Therefore, to fully understand the effects of gender on the relationship between justice and commitment, a larger, more heterogeneous sample from different cultures (e.g., individualistic and collectivistic cultures) is required. We encourage future research into similar as well as vastly different social and business cultures to be conducted to examine the issues relating to gender diversity.

The current study focussed on pay inequities based on gender, the most prevalent and controversial research area in the compensation literature. Because of the focus on pay, the finding of this study may not be applicable to other reward outcomes such as promotion opportunities, favourable assignments, recognition, etc. Future studies should address the relationship between justice and commitment with regard to a variety of outcomes.

Finally, in the current study, the pay systems of various companies were not completely known as our study focussed on perceptions of pay distribution norms. Additionally, different organisations may use different norms with regard to different aspects of pay systems (e.g., base pay, incentives, bonuses, merit pay, and benefits). Thus, it is possible that certain components of pay mix in the organisation may follow equity norms, while certain others (e.g., employee benefits) may follow equality or even need norms. We encourage future researchers to study the gender-organisational reward system relationships and their effect on employee attitudes in complex pay systems. 


\section{CONCLUSION}

The current study illustrated differences in the relationship between organisational justice and organisational commitment based on gender. The finding adds to the knowledge base in the justice, commitment, and pay equity literature. As with any study, there are some potential limitations. We used survey methodology to test the models and common method bias cannot be completely ruled out. However, as one of the reviewers pointed out, in organisational settings where we cannot perform experimental or quasi-experimental studies, cross-sectional studies are still quite useful to identify relationships among the variables of interest. Moreover, whether these findings are generalisable to other cultures remains an unresolved issue that should be addressed in future research as cultures vary on the notion of fairness and justice. Finally, the issue of justice studied in our research was focussed on pay inequities. There could be other fairness issues such as career and growth opportunities that may also influence commitment. Future studies should also address these concerns to enrich our knowledge in this area.

\section{References}

Adams, J.S. (1965). 'Inequity in social exchange', in L. Berkowitz (ed), Advances in Experimental Social Psychology, New York, NY: Academic Press.

Allen, N.J. and Meyer, J.P. (1990). 'The measurement and antecedents of affective, continuance, and normative commitment to the organization'. Journal of Occupational Psychology, 63: 1, 1-18.

Anderson, D.M. and Shinew, K.J. (2003). 'Gender equity in the context of organizational justice: A closer look at a reoccurring issue in the field'. Journal of Leisure Research, 35: 2, 228-247.

Baron, J.N. and Kreps, D.M. (1999). Strategic Human Resources: Framework for General Managers, New York, NY: John Wiley \& Sons, Inc.

Bies, R.J. and Moag, J.F. (1986). 'Interactional justice: Communication criteria of fairness', in R.J. Lewicki, B.H. Sheppard, and M.H. Bazerman (eds.), Research on Negotiations in Organizations, Greenwich, CT: JAI Press.

Campbell, D.J. and Campbell, K.M. (2003). 'Global versus facet predictors of intention to quit: Differences in a sample of male and female Singaporean managers and non-managers'. International Journal of Human Resource Management, 14: 7, 1152-1177.

Cha, Y. and Weeden, K.A. (2014). 'Overwork and the slow convergence in the gender gap in wages'. American Sociological Review, 79: 3, 457-484.

Chen, C.C., Meindl, J.R. and Hui, H. (1998). 'Deciding on equity or parity: A test of situational, cultural, and individual factors'. Journal of Organizational Behavior, 19: 2, 115-129.

Choi, S. (2011). 'Organizational justice and employee work attitudes: The federal case'. American Review of Public Administration, 41: 2, 185-204.
Cloninger, P., Ramamoorthy, N. and Flood, P.C. (2011). 'The influence of equity, equality, and gender on citizenship behaviors', SAM Advanced Management Journal, 76: 4, 37-46.

Cohen-Charash, Y. and Spector, P.E. (2001). 'The role of justice in organizations: A meta-analysis'. Organizational Behavior and Human Decision Processes, 86: 2, 278-321.

Colquitt, J.A., Conlon, D.E. Wesson, M.J., Porter, C.O. and $\mathrm{Ng}, \mathrm{K} . \mathrm{Y}$. (2001). 'Justice at the millennium: A meta-analytic review of 25 years of organizational justice research'. Journal of Applied Psychology, 86: 3, 425-445.

Conlon, D.E., Porter, C.O.L.H. and McLean-Parks, J. (2004). 'The fairness of decision rules'. Journal of Management, 30: 3, 329-349.

Cook, K.S. and Hegtvedt, K.A. (1983). 'Distributive justice, equity, and equality'. Annual Review of Sociology, 9, 217-241.

Cooper-Hakim, A. and Viswesvaran, C. (2005). 'The construct of work commitment: Testing an integrative framework'. Psychological Bulletin, 131: 2, 231-249.

Cox, T.H. (1993). Cultural Diversity in Organizations: Theory, Research, and Practice, San Francisco, CA: Berrett-Koehler Publishers, Inc.

Cropanzano. R., Bowen, D.E. and Gilliland, S.W. (2007). 'The management of organizational justice'. Academy of Management Perspectives, 21: 4, 3448.

Cropanzano, R. and Folger, R. (1991). 'Procedural justice and worker motivation', in R.M. Steers and L.W. Porter (eds), Motivation and Work Behavior (5th edn), New York, NY: McGraw Hill.

Deutsch, M. (1975) 'Equity, equality and need: What determines which value will be used as the basis 
of distributive justice?' Journal of Social Issues, 31, 137-150.

Eagly, A.H. (1987). Sex Differences in Social Behavior: A Social-Role Interpretation, Hillsdale, NJ: Erlbaum.

Eagly, A.H. and Karau, S.J. (2002). 'Role congruity theory of prejudice towards female leaders'. Psychological Review, 109: 3, 573-598.

Flood, P., Turner, T., Ramamoorthy, N. and Pearson, J. (2001). 'Causes and consequences of psychological contract among knowledge workers in the high technology and financial services industries'. International Journal of Human Resource Management, 12: 7, 1152-1165.

Foley, S., Ngo, H. and Wong, A. (2005). 'Perceptions of discrimination and justice: Are there gender differences in outcomes?' Group \& Organization Management, 30: 4, 421-450.

Gilligan, C. (1982). In a Different Voice: Psychological Theory and Women's Development, Cambridge, MA: Harvard University Press.

Gonzalez, J.A. and DeNisi, A.S. (2009). 'Cross-level effects of demography and diversity climate on organizational attachment and firm effectiveness'. Journal of Organizational Behavior, 30: 1, 21-40.

Greenberg, M.S., Block, M.W. and Silverman, M.A. (1971). 'Determinants of helping behavior: Person's rewards versus others' costs'. Journal of Personality, 39: 1, 79-93.

Haar, J.M. and Spell, C.S. (2009). 'How does distributive justice affect work attitudes? The moderating effects of autonomy'. The International Journal of Human Resource Management, 20: 8, 1827-1842.

Harris, K.J., Andrews, M.C. and Kacmar, M.K. (2007). 'The moderating effects of justice on the relationship between organizational politics and workplace attitudes'. Journal of Business and Psychology, 22: 2, 135-144.

Jensen, M.C. and Meckling, W.H. (1976). 'Theory of the firm: Managerial behavior, agency costs, and ownership structure'. Journal of Financial Economics, 3: 4, 305-360.

Jepsen, D.M. and Rodwell, J.J. (2009). 'Justice in the workplace: The centrality of social versus judgmental predictors of performance varies by gender'. International Journal of Human Resource Management, 20: 10, 2066-2083.

Johnson, R.E., Groff, K.W. and Taing, M.U. (2009a). 'Nature of interactions among organizational commitment: Complementary, competitive or synergistic?' British Journal of Management, 20: 4, 431-447.

Johnson, S., Holladay, C. and Quinones, M. (2009b). 'Organizational citizenship behavior in performance evaluations: Distributive justice or injustice?' Journal of Business and Psychology, 24, 409-418.

Kim, I.K., Park, H. and Suzuki, N. (1990). 'Reward allocations in the United States, Japan, and Korea: A comparison of individualistic and collectivistic cultures'. Academy of Management Journal, 33: 1, 188-198.

Kravitz, D.A. and Platania, J. (1993). 'Attitudes and beliefs about affirmative action: Effects of target and of respondent sex and ethnicity'. Journal of Applied Psychology, 78: 6, 928-938.

Leung, K. and Iwawaki, S. (1988). 'Cultural collectivism and distributive behavior'. Journal of Cross-Cultural Psychology, 19: 1, 35-49.

Leventhal, G.S. (1976). 'The distribution of rewards and resources in groups and organizations', in L. Berkowitz and E. Walster (eds), Advances in Experimental Social Psychology, New York, NY: Academic Press.

Li, A. and Cropanzano, R. (2009). 'Do Asians respond morelless strongly than North Americans to organizational justice? A Meta-Analysis'. Journal of Management Studies, 46: 5, 787-805.

Liao-Troth, M.A. (2001). 'Attitude differences between paid workers and volunteers'. Nonprofit Management \& Leadership, 11: 4, 423-442.

Linz, S.J. (2004). 'Motivating Russian workers: Analysis of age and gender differences'. Journal of SocioEconomics, 33: 3, 261-289.

Lowe, R.H. and Vodanovich, S.J. (1995). 'A field study of distributive and procedural justice as predictors of job satisfaction and organizational commitment'. Journal of Business and Psychology, 10: 1, 99-114.

Martín, S.S. (2008). 'Relational and economic antecedents of organisational commitment'. Personnel Review, 37: 6, 589-608.

Messarra, L. and Karkoulian, S.K. (2008). 'Organizational commitment recall in times of crisis'. Journal of International Business Research, 7: 1, 109-118.

Meyer, J.P. and Allen, N.J. (1991). 'A three-component conceptualization of organizational commitment: Some methodological considerations'. Human Resource Management Review, 1: 1, 61-98.

Milkovich, G.T., Newman, J.M. and Gerhart, B. (2014). Compensation, New York, NY: McGraw-Hill/Irwin.

Mowday, R., Porter, L. and Steers, R. (1982). 'Employee-organization linkages', in P. Warr (ed), Organizational and Occupational Psychology, New York, NY: Academic Press.

Mowday, R., Steers, R. and Porter, L. (1979). 'The measurement of organizational commitment'. Journal of Vocational Behavior, 14: 2, 224-227.

Payne, S.C. and Huffman, A.H. (2005). 'A longitudinal 
examination of the influence of mentoring on organizational commitment and turnover'. Academy of Management Journal, 48: 1, 158-168.

Pedhazur, E.J. (1982). Multiple Regression in Behavioral Research: Explanation and Prediction (2nd edn), New York, NY: Holt, Rinehart \& Winston.

Pfeffer, J. (2007). 'Human resources from an organizational behavior perspective: Some paradoxes explained'. Journal of Economic Perspectives, 21: 4, 115-134.

Peng, K.Z., Ngo, H-Y., Shi, J. and Wong, C-S. (2009). 'Gender differences in the work commitment of Chinese Workers: An investigation of two alternative explanations'. Journal of World Business, 44: 3, 323-335.

Ramamoorthy, N. and Carroll, S.J. (1998). 'Individualism/ collectivism orientations and reactions toward alternative human resource management practices'. Human Relations, 51: 5, 571-588.

Ramamoorthy, N. and Flood, P. (2004). 'Gender and employee attitudes: The role of organizational justice perceptions'. British Journal of Management, 15: 3, 547-558.

Roth, P.L., Purvis, K.L. and Bobko, P. (2012). 'A metaanalysis of gender group differences for measures of job performance in field studies'. Journal of Management, 38: 2, 719-739.

Schusterschitz, C., Geser, W., Nöhammer, E. and Stummer, H. (2011). 'Securely attached, strongly committed? On the influence of attachment orientations on organizational commitment'. Zeitschrift Für Personalforschung, 25: 4, 335-355.

Sears, D. O. and Funk, C. L. (1991). 'The role of selfinterest in social and political attitudes', in M. Zanna (ed), Advances in Experimental Social Psychology, Orlando, FL: Academic Press.

Simpson, P.A. and Kaminski, M. (2007). 'Gender, organizational justice perceptions, and union organizing'. Employee Responsibilities \& Rights Journal, 19: 1, 57-72.

Soumyaja, D., Kamalanabhan, T.J. and Bhattacharya, S. (2011). 'Employee commitment to organizational change: Test of the three component model in Indian context'. Journal of Transnational Management, 16: 4, 239-251.

Spector, P. E. (2006). 'Method variance in organizational research: Truth or urban legend?' Organizational Research Methods, 9: 2, 221-232.

Taing, M.U., Granger, B.P., Groff, K.W., Jackson, E.M. and Johnson, R.E. (2011). 'The multi-dimensional nature of continuance commitment: Commitment owing to economic exchanges versus lack of employment alternatives'. Journal of Business and Psychology, 26: 3, 269-284.

Thibaut, J. and Walker, L. (1975). Procedural Justice: A Psychological Analysis, Hillsdale, NJ: Lawrence Erlbaum Associates.

Wagner, J.A. (1995). 'Gender differences in reward preference: A status-based account'. Small Group Research, 26: 3, 353-371.

Werner, S. and Ones, D.S. (2000). 'Determinants of perceived pay inequities: The effects of comparison other characteristics and pay system communication'. Journal of Applied Social Psychology, 30: 6, 1281-1309.

Zeigler, S.L. (2006). 'Litigating equality: The limits of the equal pay act'. Review of Public Personnel Administration, 26: 3, 199-215. 